\title{
Specific interplanetary conditions for CIR-, Sheath-, and ICME-induced geomagnetic storms obtained by double superposed epoch analysis
}

\author{
Yu. I. Yermolaev, N. S. Nikolaeva, I. G. Lodkina, and M. Yu. Yermolaev \\ Space Plasma Physics Department, Space Research Institute (IKI), Russian Academy of Sciences, Profsoyuznaya 84/32, \\ Moscow 117997, Russia
}

Received: 20 September 2010 - Revised: 17 November 2010 - Accepted: 18 November 2010 - Published: 20 December 2010

\begin{abstract}
A comparison of specific interplanetary conditions for 798 magnetic storms with Dst $<-50 \mathrm{nT}$ during 1976-2000 was made on the basis of the OMNI archive data. We categorized various large-scale types of solar wind as interplanetary drivers of storms: corotating interaction region (CIR), Sheath, interplanetary CME (ICME) including both magnetic cloud (MC) and Ejecta, separately MC and Ejecta, and "Indeterminate" type. The data processing was carried out by the method of double superposed epoch analysis which uses two reference times (onset of storm and minimum of Dst index) and makes a re-scaling of the main phase of the storm in a such way that all storms have equal durations of the main phase in the new time reference frame. This method reproduced some well-known results and allowed us to obtain some new results. Specifically, obtained results demonstrate that (1) in accordance with "output/input" criteria the highest efficiency in generation of magnetic storms is observed for Sheath and the lowest one for MC, and (2) there are significant differences in the properties of MC and Ejecta and in their efficiencies.
\end{abstract}

Keywords. Magnetospheric physics (Solar windmagnetosphere interactions)

\section{Introduction}

One of the important aims of the Solar-Terrestrial Physics is the investigation of interplanetary drivers of magnetic storms. It has been well-known for a long time that the most important parameter leading to geomagnetic distur-

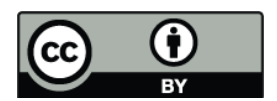

Correspondence to: Yu. I. Yermolaev (yermol@iki.rssi.ru) bances and, in particular, to magnetic storm generation is negative (southward) $B_{\mathrm{Z}}$ component of interplanetary magnetic field (IMF) (Dungey, 1961; Fairfield and Cahill, 1966; Rostoker and Falthammar, 1967; Russell et al., 1974; Burton et al., 1975; Akasofu, 1981). Because IMF lies in the ecliptic plane under steady interplanetary conditions and substantial $B_{\mathrm{Z}}<0$ is observed only in disturbed types of solar wind (SW), it was found in many investigations that interplanetary coronal mass ejections (ICME) and corotating interaction regions (CIR) are the most important drivers of magnetic disturbances on the Earth. Therefore, it is natural to categorize these solar wind drivers during a study of magnetic storm generation (see reviews and recent papers, for instance, Tsurutani et al., 1988; Tsurutani and Gonzalez, 1997; Gonzalez et al., 1999; Yermolaev and Yermolaev, 2002; Huttunen and Koskinen, 2004; Echer and Gonzalez, 2004; Yermolaev et al., 2006; Borovsky and Denton, 2006; Denton et al., 2006; Huttunen et al., 2006; Yermolaev et al., 2007a,b,c; Pulkkinen et al., 2007a,b; Zhang et al., 2007; Turner et al., 2009; Yermolaev et al., 2010b, and references therein). As shown by numerous researchers, the different interplanetary drivers result in specific reactions of magnetosphere, for example, CIR- and ICME-induced magnetic storms (Huttunen et al., 2002; Borovsky and Denton, 2006; Pulkkinen et al., 2007a) or the specific development of substorms (Despirak et al., 2009). However, the question of what specific (additional to main geoeffective parameter $B_{\mathrm{Z}}<0$ ) interplanetary conditions result in specific magnetic storm features is still open and it does not allow us to precisely predict the reaction of the magnetosphere. The progress in solving this problem may be connected to the development of methodical approaches.

Usage of the "peak-to-peak" method where the minimum of IMF $B_{\mathrm{z}}<0$ (or electric field $\boldsymbol{E}_{\mathrm{y}}=\boldsymbol{V}_{\mathrm{x}} \times \boldsymbol{B}_{\mathrm{z}}$ ) was compared with extreme values of the Dst and $\mathrm{Kp}$ indices did

Published by Copernicus Publications on behalf of the European Geosciences Union. 
Table 1. List of results on interplanetary conditions resulting in magnetic storms obtained by superposed epoch analysis.

\begin{tabular}{|c|c|c|c|c|c|}
\hline $\mathrm{N}$ & Number (Years) & Zero time & Selection & SW and IMF & Reference \\
\hline 1 & $538(1963-1991)$ & onset & No & $B, B_{\mathrm{x}}, B_{\mathrm{y}}, B_{\mathrm{z}}, V, T, n, P_{\mathrm{dyn}}$ & Taylor et al. (1994) \\
\hline 2 & $120(1979-1984)$ & $\min$ Dst & No & $B_{\mathrm{Z}}, n, V$ & Maltsev et al. (1996) \\
\hline 3 & $150(1963-1987)$ & turning $B_{\mathrm{Z}}$ & No & $B_{\mathrm{Z}}, P_{\mathrm{dyn}}$ & Davis et al. (1997) \\
\hline 4 & $305(1983-1991)$ & onset & No & $B_{\mathrm{Z}}, P_{\mathrm{dyn}}$ & Yokoyama and Kamide (1997) \\
\hline 5 & 1085 (1957-1993) & $\min$ Dst & Dst & $B_{\mathrm{z}}, P_{\mathrm{dyn}}$ & Loewe and Prolss (1997) \\
\hline 6 & $130(1966-2000)$ & onset & No & $\begin{array}{l}B, B_{\mathrm{X}}, B_{\mathrm{y}}, B_{\mathrm{Z}},\left|B_{\mathrm{X}}\right|,\left|B_{\mathrm{y}}\right| \\
\left|B_{\mathrm{Z}}\right|, V, n, P_{\mathrm{dyn}}\end{array}$ & Lyatsky and Tan (2003) \\
\hline 7 & $623(1976-2000)$ & onset and min Dst & SW types ${ }^{\mathrm{a}}$ & $\begin{array}{l}B, B_{\mathrm{x}}, B_{\mathrm{y}}, B_{\mathrm{z}}, V, T, n, P_{\mathrm{dyn}}, \\
\mathrm{nkT}, \beta, T / T_{\exp }\end{array}$ & Yermolaev et al. $(2005,2006,2007 \mathrm{c}, \mathrm{a})$ \\
\hline 8 & 78 (1996-2004) & $\min$ Dst & SW types ${ }^{b}$ & $B, B_{\mathrm{Z}}, d B / B, V, T, n$ & Miyoshi and Kataoka (2005) \\
\hline 9 & 549 (1974-2002) & $\min$ Dst & $\mathrm{Yes}^{\mathrm{c}}$ & $\begin{array}{l}B, B_{\mathrm{X}}, B_{\mathrm{y}}, B_{\mathrm{z}},\left|B_{\mathrm{x}}\right|,\left|B_{\mathrm{y}}\right|, \\
\left|B_{\mathrm{Z}}\right|, B_{\mathrm{S}}, V B_{\mathrm{S}}, V, n, T, P_{\mathrm{dyn}}\end{array}$ & Zhang et al. (2006) \\
\hline 10 & $623(1976-2000)$ & onset & SW types ${ }^{\mathrm{a}}$ & $\sigma B, \sigma V, \sigma T, \sigma n$ & Yermolaev et al. (2007b) \\
\hline 11 & $28(1997-2002)$ & onset and min Dst & SW types ${ }^{\mathrm{d}}$ & $B_{\mathrm{z}}, P_{\mathrm{dyn}}, V, E_{\mathrm{y}}$ & Pulkkinen et al. (2007a) \\
\hline 12 & $10(2004)$ & onset & No & $\begin{array}{l}B_{\mathrm{x}}, B_{\mathrm{y}}, B_{\mathrm{z}}, B, \epsilon, V, n, P_{\mathrm{dyn}} \\
M_{\mathrm{A}}, E_{\mathrm{y}}\end{array}$ & Pulkkinen et al. (2007b) \\
\hline 13 & 29 (1999-2002) & $\begin{array}{l}\text { onset,main phase, } \\
\text { min Dst }\end{array}$ & No & $B_{\mathrm{Z}}, P_{\mathrm{dyn}}$ & Ilie et al. (2008) \\
\hline 14 & $280(1995-2004)$ & $\min$ Dst & SW types ${ }^{b}$ & $B_{\mathrm{Z}}, V, \epsilon, M_{\mathrm{A}}$ & Turner et al. (2009) \\
\hline
\end{tabular}

a (1) CIR, (2) Sheath and (3) MC; b (1) CIR and (2) MC (Sheath + MC body); ${ }^{\mathrm{c}}$ (1) moderate storm at solar minimum, (2) moderate storm at solar maximum, (3) strong storm at solar minimum, and (4) strong storm at solar maximum; ${ }^{\mathrm{d}}$ (1) MC and (2) Sheath.

not allow one to find significant differences between these interplanetary and magnetospheric parameters for magnetic storms generated by different drivers (see, for instance, Yermolaev et al., 2007b, and references therein). Analysis of time evolution in interplanetary parameters using the superposed epoch analysis (SEA) method was more informative and showed some characteristic conditions during storms and several differences in interplanetary parameters for different drivers (see Table 1). Although the CIR, ICME and Sheath (compressed region before ICME) as important drivers of magnetic storms have been discussed in the literature for a long time (Tsurutani et al., 1988; Gosling et al., 1991; Tsurutani and Gonzalez, 1997; Vieira et al., 2004; Huttunen and Koskinen, 2004; Yermolaev et al., 2005; Yermolaev and Yermolaev, 2006; Alves et al., 2006; Borovsky and Denton, 2006), some authors still did not separate large-scale types of solar wind for superposed epoch analysis (Denton et al., 2005; Zhang et al., 2006; Liemohn et al., 2008; Ilie et al., 2008) or Sheath and body of ICME (Denton et al., 2006; Borovsky and Denton, 2006; Turner et al., 2009). Only recent papers analysed separately CIR, Sheath and body of ICME (Huttunen and Koskinen, 2004; Yermolaev et al., 2006; Huttunen et al., 2006; Yermolaev et al., 2007a,b,c; Pulkkinen et al., 2007a; Yermolaev et al., 2010b,a).

The choice of zero (reference) time for SEA is important and substantially influences the results (Yermolaev et al., 2006, 2007c; Ilie et al., 2008). In the most part of the previous papers, the authors used the peak of $|\mathrm{Dst}|$ index as a zero time for SEA (Maltsev et al., 1996; Loewe and Prolss, 1997; Zhang et al., 2006). This choice is convenient only for studying the end of the main phase and the beginning of the recovery phase of storms. However, inside of a near-onset interval with a duration of several hours the parameters measured before and after onset are averaged simultaneously because the duration of the main phase lasts from 2 to $15 \mathrm{~h}$ (Vichare et al., 2005; Gonzalez and Echer, 2005; Yermolaev et al., 2006, 2007a), and specific conditions resulting in storm onset cannot be studied. The onset time as zero time of SEA allows one to investigate interplanetary sources and the initial part of the storms, but specific conditions resulting in termination of the main phase of the storm cannot be studied (Yermolaev et al., 2006, 2007a,b,c; Pulkkinen et al., 2007a). For example, this analysis showed that storms initiated by Sheath have sharper and shorter main phase than storms initiated by other interplanetary drivers (Yermolaev et al., 2007a; Pulkkinen et al., 2007a).

Efficiencies of various interplanetary drivers vary with the type of solar wind and may be estimated as the ratio of measured energy output to estimated energy input (see, for example, paper by Turner et al. (2009), and references therein). In our investigations, we use $B_{\mathrm{z}}\left(E_{\mathrm{y}}\right)$ and magnetospheric indices Dst, Dst* (pressure corrected Dst), Kp and AE as "input" and "output" of the storm generation processes for the estimation of efficiency of interplanetary drivers.

In this paper, we study interplanetary conditions resulting in magnetic storms on the basis of the OMNI database during 
1976-2000 and categorize 6 types of solar wind: (1) CIR, (2) ICME including both two types of ICME - Magnetic cloud (MC) and Ejecta, (3) MC, (4) Ejecta, (5) Sheath before MC and Ejecta, and (6) "Indeterminate" type (OMNI does not contain sufficient information for identification of the type). We use "double" (with two reference times) SEA method, that is, we re-scale the duration of the main phase of all storms in such a manner that, respectively, onsets and minima of Dst index for all storms coincide and study interplanetary conditions leading to the start and end of the main phase of magnetic storms induced by these 6 interplanetary drivers.

\section{Method}

The basis of our investigation is 1-h interplanetary and magnetospheric data of OMNI database (King and Papitashvili, 2004). We made our own data archive including OMNI data and calculated (using OMNI data) additional parameters including thermal and dynamic pressures, plasma $\beta$ parameters (ratio of thermal and magnetic field pressures), ratio of measured temperature and temperature estimated on the basis of average velocity-temperature relation and others. Using threshold criteria for key parameters of SW and IMF (velocity, temperature, density, ratio of thermal to magnetic pressure, magnitude and orientation of magnetic field, etc.), we defined corresponding large-scale types of SW and the possible error of this identification for every 1-h point of the archive during 1976-2000 (see paper by Yermolaev et al., 2009, and site ftp://ftp.iki.rssi.ru/pub/omni/). Our identification of SW types is based on methods similar to ones described in many papers (see reviews by WimmerSchweingruber et al., 2006, and Tsurutani et al., 2006, and references therein) and basically agrees with the results of other authors, but in contrast with other similar studies, we used a general set of threshold criteria for all SW types and made the identification for each 1-h point.

During 1976-2000, there were 798 magnetic storms with Dst $<-50 \mathrm{nT}$. There were data gaps in several parameters of the OMNI database for $334(42 \%)$ from them (these storms are denoted as "Indeterminate", IND) and interplanetary drivers were found for 464 storms (Yermolaev et al., 2010b). A magnetic storm is considered to be connected with specific SW type if its onset is observed in $2 \mathrm{~h}$ after the beginning and during this SW type $(2 \mathrm{~h}$ interval is the average delay between the appearance of southward IMF and the reaction of magnetosphere (Gonzalez and Echer, 2005; Yermolaev et al., 2007a,c). In accordance with this procedure, a small number of double-step storms caused by the combined effect of the Sheath + ICME (e.g., Kamide et al., 1998) was identified as Sheath-induced storms. The statistics of magnetic storm distribution over different types of SW is the following: 145 storms were induced by CIR, $62-\mathrm{MC}, 161$ Ejecta, 96 - Sheath (12 before MC and 84 before Ejecta)
(Yermolaev et al., 2010b). In our previous papers, (Yermolaev et al., 2006, 2007a,b,c) we considered magnetic storms with Dst $<-60 \mathrm{nT}$ and the statistics of storms was a bit different (total number of storms is 623).

As has been indicated above, the duration of the main phase of magnetic storms varies in a wide range of $2-15 \mathrm{~h}$ (Vichare et al., 2005; Gonzalez and Echer, 2005; Yermolaev et al., 2006, 2007a), average duration during the interval of 1976-2000 is $7 \pm 4 \mathrm{~h}$ (Yermolaev et al., 2006, 2007a). We use SEA with 2 reference time instants and located all onsets at " 0 " time of epoch and all Dst minima at " 6 " time. The times before onset ( $t \leq$ " 0 " time) and after Dst minimum ( $t \geq$ " 6 " time) are real, but the time between onset and Dst minimum was re-scaled (proportionally increased/decreased). After this transformation, all storms have equal durations of main phase in the new time reference frame. Thus " $0-6$ " interval of main phase has two 1 -h points ( $t=$ " 0 " and " 6 ") and 5 equal sub-intervals (points with $t=$ " $1-5$ ") (see more details in the paper by Yermolaev et al., 2010a). The time in the " 0 "" 6 " interval for $2 / 3$ storms was changed not more than by $1 / 3$ of its duration. This "double" SEA method allows us to simultaneously study interplanetary conditions resulting in the beginning and end of magnetic storms as well as dynamics (temporal variations) of parameters for storms with different durations.

Taking into account that the typical durations of largescale SW types are significantly shorter than the full duration of magnetic storms (see, for example, papers by Crooker et al., 1999; Gosling and Pizzo, 1999; Lynch et al., 2003; Lepping et al., 2005), and averaging $9 \pm 4,28 \pm 12$ and $20 \pm 8 \mathrm{~h}$ for Sheath, ICME and CIR, respectively (Yermolaev et al., 2007c), we restricted the durations of curves calculated using double SEA by time from -12 up to $+24 \mathrm{~h}$. It is important that statistics decreases from the main phase of storms to the edges of $(-12,+24)$ interval (especially for Sheaths) and errors may increase at the edges of interval (Standard deviations for different parameters and different interplanetary drivers are similar to data presented by Yermolaev et al., 2007c). In cases discussed below, differences between the curves in figures are mathematically significant although sometimes they are less than corresponding standard deviations. In some other cases it is necessary to consider these differences as a tendency (hypothesis) rather than a proven physical fact. Further investigations are required to reduce this uncertainty.

\section{Results}

Figures 1 and 2 present the time variation of several interplanetary and magnetospheric parameters for 798 magnetic storms with Dst $<-50$ nT during 1976-2000, which were obtained by the double SEA method with 2 reference epoch zero times: Dst storm onset and Dst minimum (dashed lines which cross " 0 " and " 6 " in the time 
ALL storms

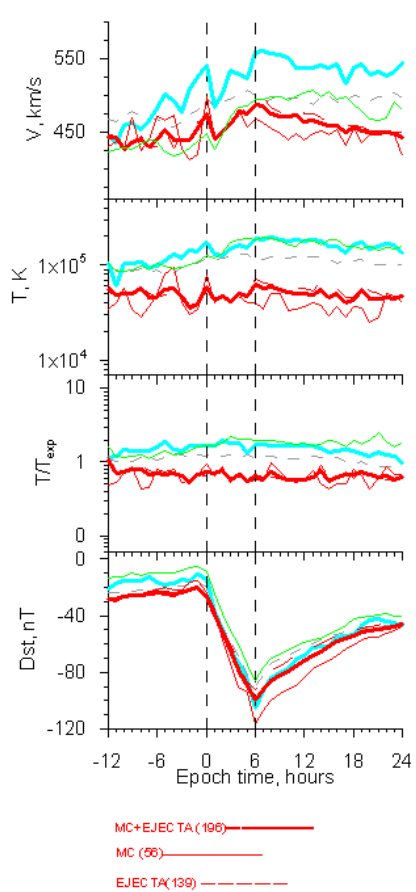

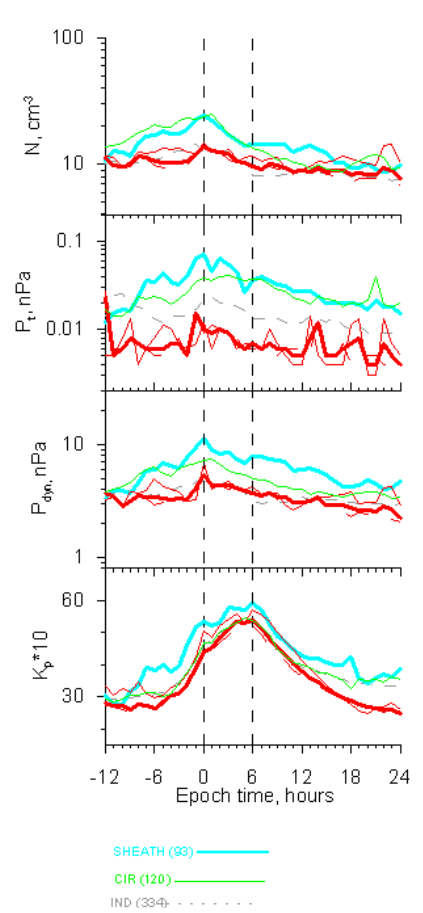

Fig. 1. Behaviour of interplanetary parameters and magnetospheric Dst and Kp indices for magnetic storms with Dst $<-50 \mathrm{nT}$ generated by different interplanetary drivers: (1) all ICME (MC+Ejecta), (2) MC, (3) Ejecta, (4) Sheath, (5) CIR, and (6) "Indeterminate" (see designations in bottom of figure) during 1976-2000 on the basis of OMNI database obtained by double superposed epoch analysis method with two reference times: onset (" 0 " time, 1 st dashed line) and minimum Dst index ("6" time, 2nd dashed line). Presented parameters: (left column) $V$ - velocity, $T$ - proton temperature, $T / T_{\exp }$ - ratio of measured proton temperature to calculated temperature $T_{\text {exp }}$ using average dependence of temperature on velocity $V$ (Lopez and Freeman, 1986), Dst index, (right) $n-$ density, $P t-$ thermal pressure, $P_{\text {dyn }}-$ dynamic pressure, Kp index.

axis of figures, respectively) and for 6 interplanetary drivers: (1) MC, (2) Ejecta, (3) sum of MC and Ejecta, (4) Sheath (sum of Sheaths before MC and Ejecta), (5) CIR, and (6) IND ("Indeterminate") type of SW. Curves for different types of solar wind are presented by different colors. Under figure designations and the number of events for each SW type are specified, the number of points in a separate bin of curves in figures can be less than the specified number of events, especially at the interval edges. Figure 1 shows: (left column) $V$ - velocity, $T$ - proton temperature, $T / T_{\exp }$ - ratio of the measured proton temperature to calculated temperature $T_{\exp }$ using an average dependence of temperature on velocity $V$ (Lopez and Freeman, 1986), Dst index, (Right) $n$ - density, $P t-$ thermal pressure, $P_{\text {dyn }}-$ dynamic pressure, Kp index. Figure 2 presents other parameters: (left column) $E_{\mathrm{y}}-$ electric field, $B_{\mathrm{Z}}-$ GSM southward components of IMF, Dst* dynamic pressure-corrected Dst index (Burton et al., 1975),

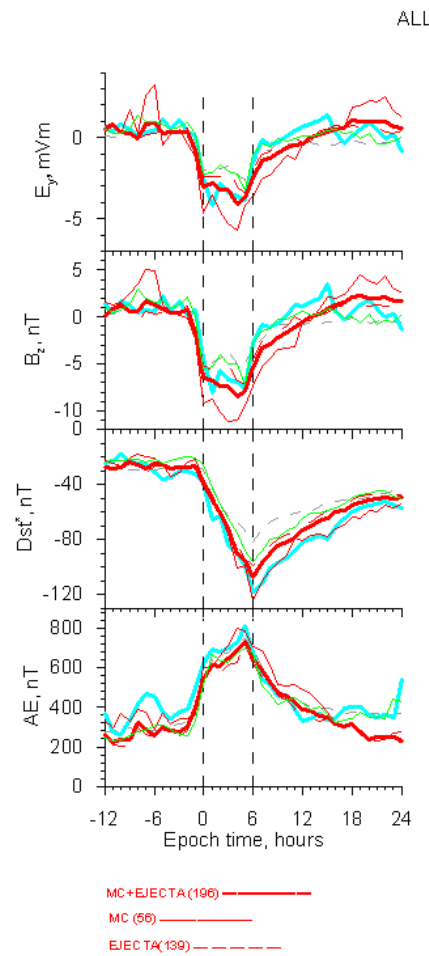

ALL storms

Fig. 2. The same as in Fig. 1 for parameters: (left column) $E_{\mathrm{y}}$ - electric field, $B_{\mathrm{Z}}-$ GSM southward components of IMF, Dst* - dynamic pressure-corrected Dst index (Burton et al., 1975), AE index, (right) $B_{\mathrm{y}}, B_{\mathrm{X}}, B-\mathrm{GSM}$ components and magnitude of IMF, $\beta$ - ratio of thermal to magnetic pressure.

AE index, (right) $B_{\mathrm{y}}, B_{\mathrm{x}}, B$ - GSM components and magnitude of IMF, $\beta$ - ratio of proton thermal to magnetic pressure.

For all interplanetary drivers of magnetic storms the onset starts in $1-2 \mathrm{~h}$ after southward turning of IMF $\left(B_{\mathrm{Z}}<0\right)$ and the main phase stops in $1-2 \mathrm{~h}$ after the abrupt drop of the southward IMF component. In a new time scale in the region of " 0 "-" 6 " there is no significant difference between the behaviour of Dst (Dst*) index for different drivers. Nevertheless, it is possible to indicate a slight tendency that the most sharp decrease of indices is observed for Sheath and $\mathrm{MC}$, while the largest values of southward component of IMF and electric field are in MC. The highest values of Kp and $\mathrm{AE}$ indices are generated by Sheath and MC. Slope of Dst (Dst*) index and values of $\mathrm{Kp}$ and $\mathrm{AE}$ indices for Ejecta and $\mathrm{MC}+$ Ejecta are less than for MC, and this fact is one of the most important reasons why we did not consider all ICME together and made the selection of two subtypes of ICME: MC and Ejecta. The highest value of velocity $V$ is observed in Sheath (difference relative to another curves is $70-100 \mathrm{~km} / \mathrm{s}$ ), temperature $T$ and $T / T_{\exp }$ (2-3 times) in Sheath and CIR, density $n$ (1.5-2.0 times) in Sheath and CIR, thermal pressure $P t$ (5-7 times) in Sheath, dynamic pressure $P_{\text {dyn }}(1.5-2.0$ times) in Sheath and CIR, $\beta$ (1.5-2.0 times) in Sheath and CIR, IMF magnitude $B(2-5 \mathrm{nT})$ in Sheath, 
Storms with $-100<D s t<-50 n T$

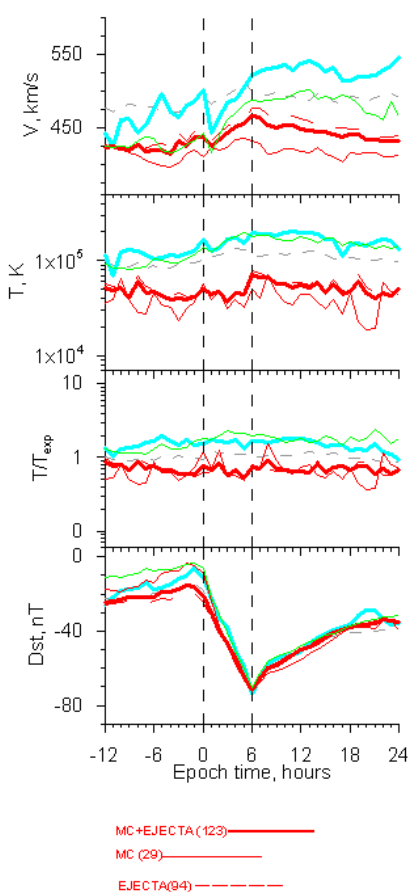

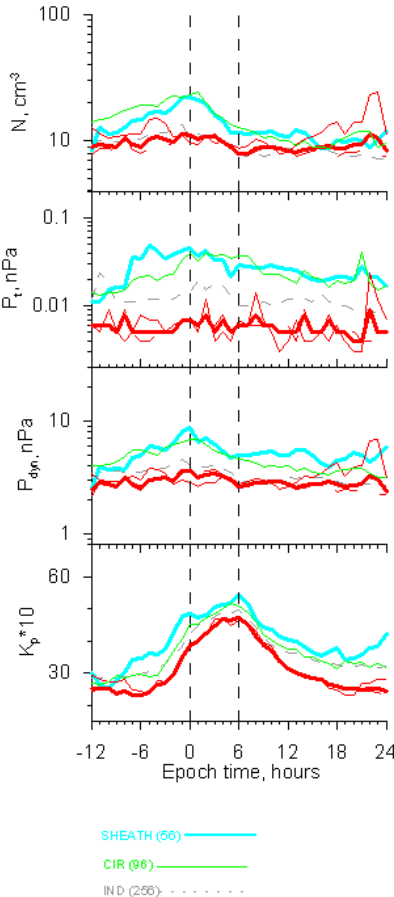

Fig. 3. The same as in Fig. 1 for moderate storms with $-100<$ Dst $<-50$ nT.

$\mathrm{MC}$ and CIR. There is no systematic difference in $B_{\mathrm{x}}$ and $B_{\mathrm{y}}$ components of IMF for the different SW types in the region of " 0 "- " 6 " time.

To study the behaviour of interplanetary parameters separately during moderate and strong storms, we divided data presented in Figs. 1 and 2 in two groups with $-100<$ Dst $<$ $-50 \mathrm{nT}$ (see Figs. 3 and 4 ) and Dst $<-100 \mathrm{nT}$ (Figs. 5 and 6). This selection decreased data statistics in the new figures, especially for Figs. 5 and 6 (see number of events under figures) when the number of points in a separate bin of curves at interval edges can be less than 10. Taking into account the accuracy of our estimations, it is possible to tell that all the specified above tendencies and features of relative behaviour of SW and IMF parameters and magnetospheric indices for different interplanetary drivers are the same for both storm sizes.

One of important problems of connection between interplanetary conditions and magnetospheric processes is the dependence of magnetospheric activity on temporal evolution of SW and IMF parameters including $B_{\mathrm{z}}$ and $E_{\mathrm{y}}$. We found a consistency between time evolution of cause $\left(B_{\mathrm{z}}\right.$ and $\left.E_{\mathrm{y}}\right)$ and time evolution of effect (Dst, Dst*, Kp and AE indices) for the time interval of "0"-" 6 " using 3 procedures (see Figs. 79):

1. (Left column in figures where abscissa is designated as $E_{\mathrm{y}}$ and $\left.B_{\mathrm{z}}\right)$
Storms with $-100<D s t<-50 n T$
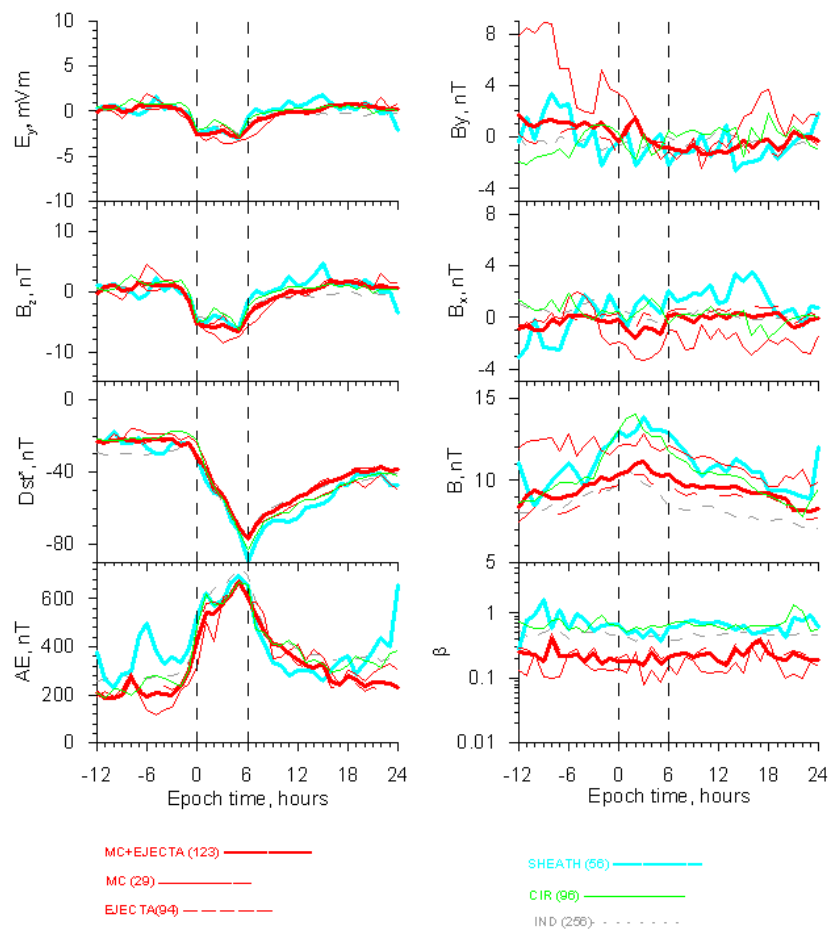

Fig. 4. The same as in Fig. 2 for moderate storms with $-100<$ Dst $<-50$ nT.

simultaneous measurements, for example, dependence of $\operatorname{Dst}\left(t^{i}\right)$ vs. $E_{\mathrm{y}}\left(t^{i}\right), i=0, \ldots, 6$,

2. (Second column, abscissa is designated as $E_{\mathrm{y}}(t-1)$ and $\left.B_{\mathrm{Z}}(t-1)\right)$

1-h displaced measurements, for example, Dst $\left(t^{i}\right)$ vs. $E_{\mathrm{y}}\left(t^{i-1}\right), i=0, \ldots, 6$, and

3. (Right column, abscissa is designated as $E_{\mathrm{y}}\left(\sum\right)$ and $\left.B_{\mathrm{Z}}\left(\sum\right)\right)$

dependence of indices on integral value of sources, for example, Dst ${ }^{i}$ vs. $E_{\mathrm{y}}\left(\sum\right)^{i}=\int_{0}^{t^{i}} E_{\mathrm{y}}(\tau) d \tau=\sum_{0}^{i} E_{\mathrm{y}}^{k}, i=$ $0, \ldots, 6 ; k=0, \ldots, i$. It is important to be reminded that all storms have equal durations in interval of " 0 "-" 6 ".

The left column of Fig. 7 shows that there is no monotonic relation between interplanetary conditions and magnetospheric indices. If we take into account the 1-h delay between sources and effects (the second column), dependencies become more monotonic, i.e., there is a delay between cause and effect. The right column of the figure demonstrates that discussed processes have a "memory" and all dependencies are monotonic and almost linear. Figure 7 allows us to compare "input (several combinations of $B_{\mathrm{z}}$ or $E_{\mathrm{y}}$ )" and "output (several magnetospheric indices)" during the process of storm generation. This comparison shows that the most 
Storms with Dst<-100 nT
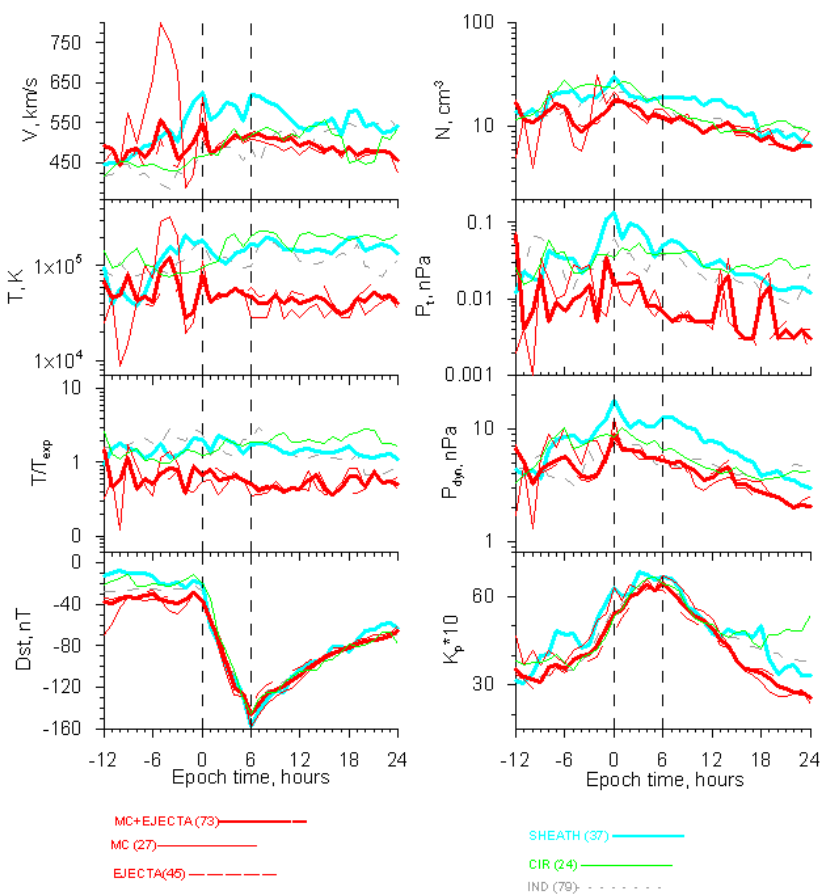

Fig. 5. The same as in Fig. 1 for strong storms with Dst $<-100 \mathrm{nT}$.
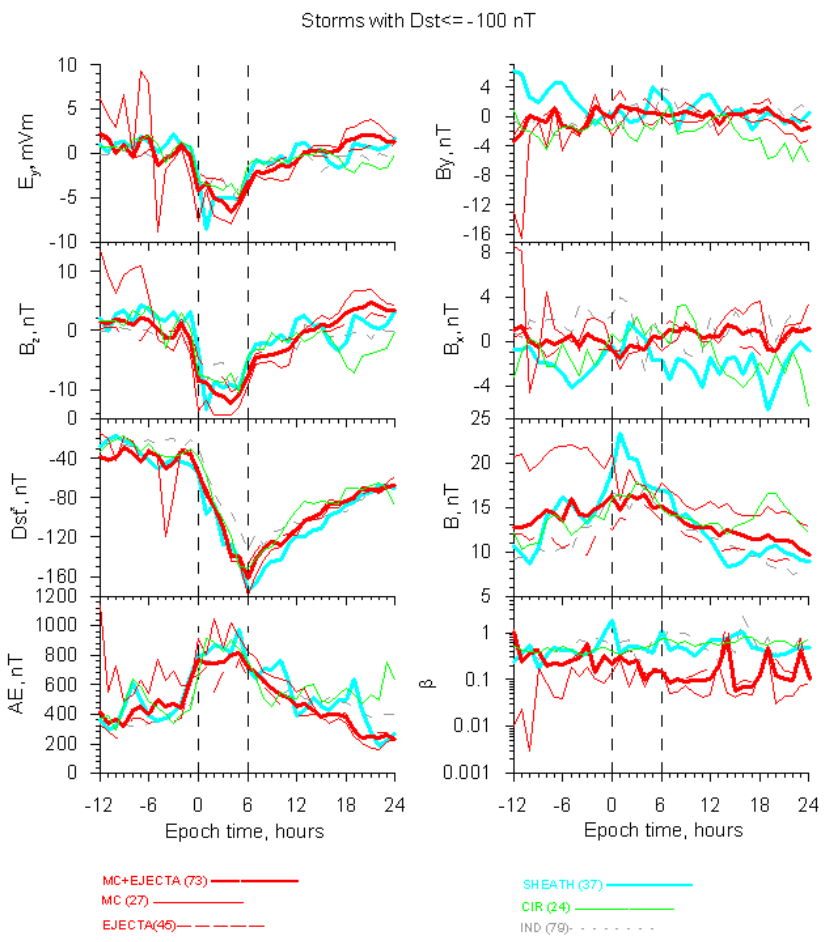

Fig. 6. The same as in Fig. 2 for strong storms with Dst $<-100 \mathrm{nT}$.
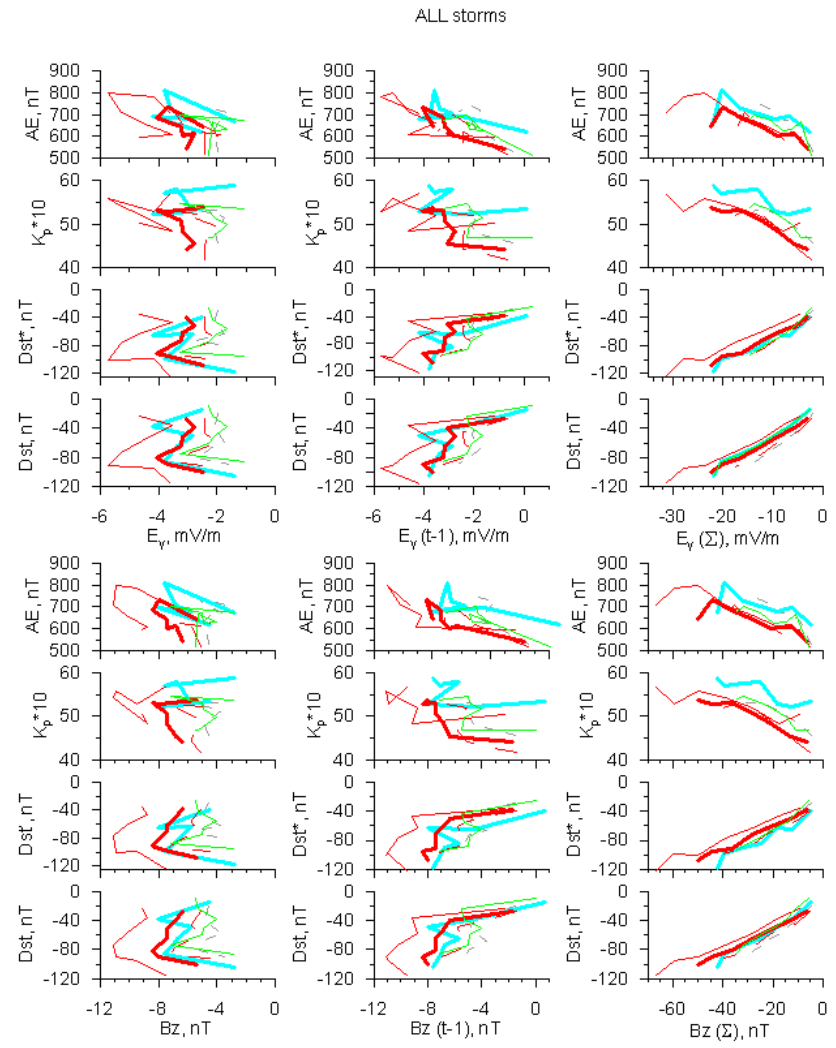

MC+EJECTA $(196)-\square$

EJECTA(139) - - - - -

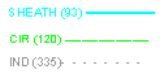

Fig. 7. Time evolution of Dst, Dst*, Kp and AE indices during time evolution of $B_{\mathrm{z}}$ and $E_{\mathrm{y}}$ for time interval of " 0 "-" 6 " using 3 procedures (see text): (1. left column) simultaneous measurements, (2. second column) 1-h displaced measurements, and (3. right column) dependence of indices on integral value of sources.

effective process of $\mathrm{Kp}$ and $\mathrm{AE}$ indices generation acts during Sheath, CIR and IND, the least effective process of Dst and Dst* generation - during MC. The additional selection of Fig. 7 data on storm size with $-100<$ Dst $<-50 \mathrm{nT}$ and Dst $<-100 \mathrm{nT}$ (see Figs. 8 and 9, respectively) shows that main properties specified in Fig. 7 remain in the new figures.

\section{Discussion and conclusions}

We performed an analysis of interplanetary conditions for 798 magnetic storms with Dst $<-50 \mathrm{nT}$ during 1976-2000 on the basis of the OMNI archive data. Our analysis has two new special features. (1) Taking into account the importance of epoch time selection, we used the method of the double superposed epoch analysis including simultaneously two reference times: the onset of storm and the minimum of Dst index. (2) Taking into account the different reactions of magnetosphere on various interplanetary disturbances, we use sufficiently full classification and categorized large-scale 
Storms with $-100<\mathrm{Dst}<-50$
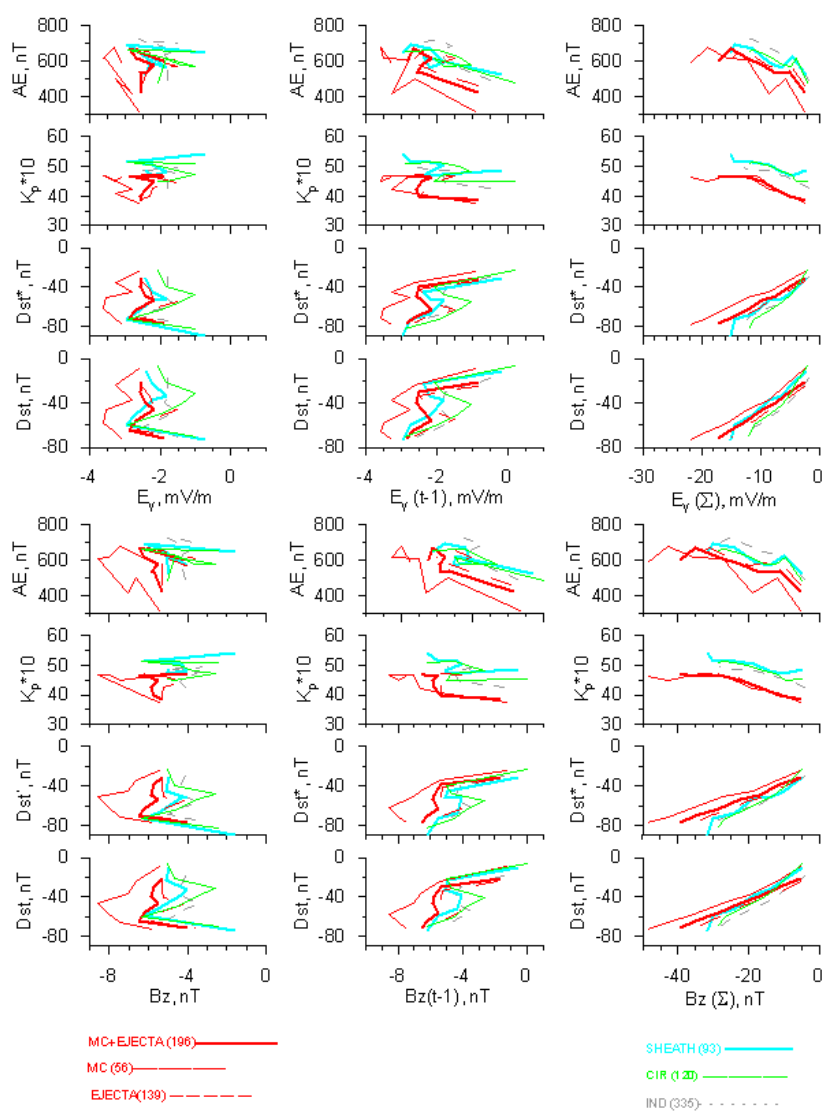

CHEJECTA $(196)$

EJECTA(139)----

$\ln (335)$

Fig. 8. The same as in Fig. 7 for moderate storms with $-100<$ Dst $<-50$ nT.

types of solar wind as interplanetary drivers of storms: CIR, Sheath, MC, Ejecta, ICME (e.g., both MC and Ejecta) and "Indeterminate" type. This analysis was made taking into account possible distinctions of moderate and strong magnetic storms. This methodical approach showed the following.

First of all, we would like to note that our method reproduced some well-known results and, in particularly, showed that independently on types of interplanetary drivers, the onset of magnetic storms begins in 1-2 $\mathrm{h}$ after southward turn of IMF and the recovery phase of storms begins in $1-2 \mathrm{~h}$ after the abrupt drop of this component of IMF (small value of southward component of IMF may be observed during several hours after the minimum of Dst during recovery phase of storm) (see Figs. 1-6).

Various types of interplanetary drivers of magnetic storms have significantly different parameters. Particularly, Sheath and CIR (with respect to ICME) have higher density, dynamic and thermal pressures, temperature, $\beta$-parameter as well as a higher variance of the same parameters and magnitude and components of IMF. These differences can be significant, for example, dynamic pressure is larger by a factor of 1.5-2. The comparison of values of $B_{\mathrm{z}}\left(E_{\mathrm{y}}\right)$ and Dst index
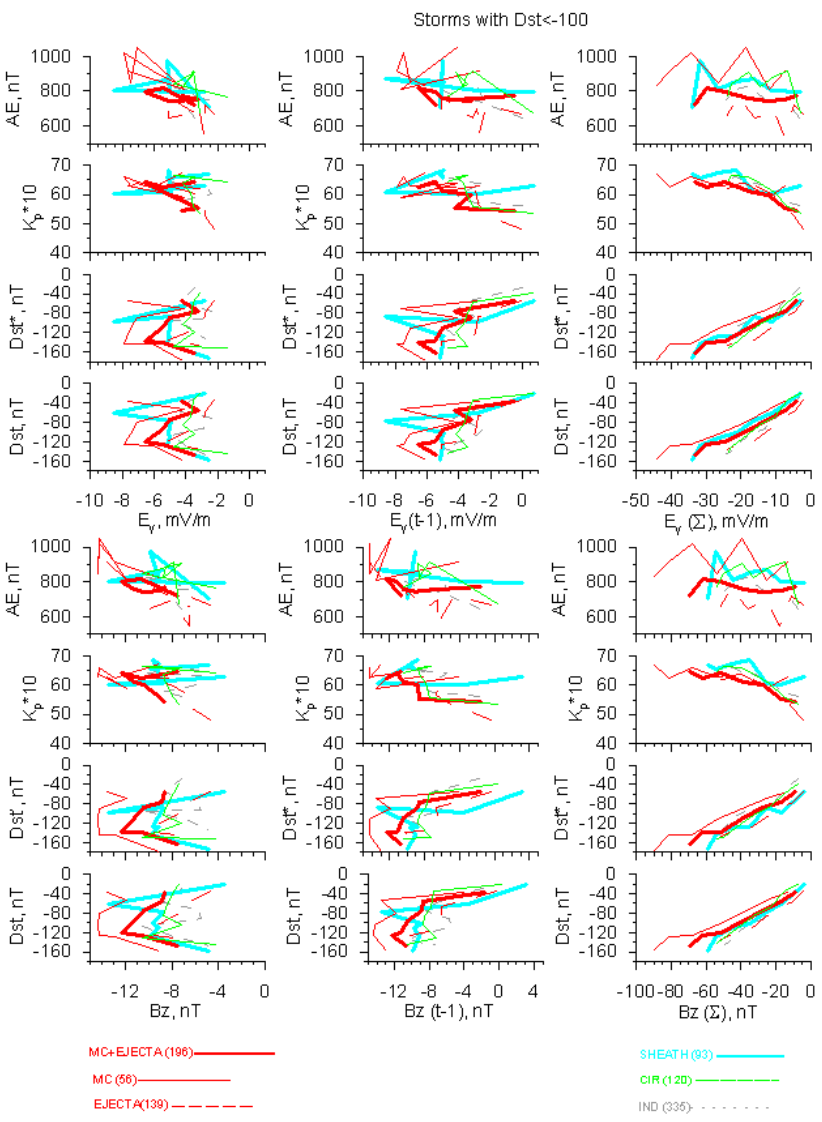

Fig. 9. The same as in Fig. 7 for strong storms with Dst $<-100 \mathrm{nT}$.

for different drivers confirms high importance (Tsurutani et al., 1988; Tsurutani and Gonzalez, 1997) and high efficiency (Huttunen and Koskinen, 2004; Yermolaev et al., 2006; Huttunen et al., 2006; Yermolaev et al., 2007a,b,c; Pulkkinen et al., 2007a; Turner et al., 2009) of Sheath in the generation of magnetic storms and indicates specific geoeffective conditions in Sheath. It is important to note that there are significant differences in parameters of MC and Ejecta (including their efficiencies), while differences in Sheath before MC and Sheath before Ejecta are not significant (Yermolaev et al., 2009, 2010b). Confirmation of results earlier obtained by different methods is a good verification of the used method. At the same time the new method allowed us to obtain some new results.

Using double SEA method (transformation of main phases of storms to equal duration) allowed us to compare storms with different durations of main phase. In the re-scaled temporal reference frame the Dst.vs.time (Dst*. vs. time) dependencies for storms induced by different types of interplanetary drivers are close to each other and have approximately linear shapes in time interval of "0"-"6". Comparison of Dst vs. time and Dst*. vs. time dependencies for storms induced by Sheath showed that dynamic pressure $P_{\text {dyn }}$ results in parallel displacement of Dst(Dst*). vs. time dependencies 
but does not change shape and slope of these dependencies. Though our transformation should mask the shorter main phase for Sheath-induced storms (Yermolaev et al., 2007a; Pulkkinen et al., 2007a), our results obtained by double SEA method (see Figs. 1-6) speak in favour that the Dst.vs.time (Dst*. vs.time) dependencies for storms induced by Sheath are more abrupt than for storms induced by another drivers. The Kp. vs. time and AE. vs. time dependencies are nonlinear and higher for Sheath- than for CIR- and ICME-induced storms. It means that these indices are generated by other mechanisms than Dst and Dst* indices.

We studied dependencies of several geomagnetic (Dst, Dst*, $\mathrm{Kp}$ and $\mathrm{AE}$ ) indices on current, previous and integrated $B_{\mathrm{z}}$ and $E_{\mathrm{y}}$ components for different interplanetary drivers (Figs. 7-9). These dependencies are efficiencies of storm generation by different drivers in accordance with "output/input" criteria. Dependencies of Dst (or Dst*) on the integral of $B_{\mathrm{z}}$ (or $E_{\mathrm{y}}$ ) over time are almost linear and parallel for different types of drivers. This fact can be considered as an indication that time evolution of main phase of storms depends not only on current values of $B_{\mathrm{z}}$ and $E_{\mathrm{y}}$, but also on their prehistory. The differences between these lines are relatively small $(\Delta \mathrm{Dst}<20 \mathrm{nT})$. Nevertheless we can make following conclusions: (1) efficiency of storm generation by $\mathrm{MC}$ is the lowest one (i.e., at equal values of integrated $B_{\mathrm{Z}}$ or $E_{\mathrm{y}}$ the storm is smaller than for another drivers), (2) efficiency for Ejecta is higher than for MC, (3) efficiency for Sheath is the highest one. Dependencies of $\mathrm{Kp}$ (and AE) on integral of $B_{\mathrm{z}}$ (and $E_{\mathrm{y}}$ ) over time are nonlinear (There is the saturation effect for $\mathrm{AE}$ index) and nonparallel. The differences between these lines are relatively small $(\Delta K p<1$ and $\Delta \mathrm{AE}<50 \mathrm{nT}$ ), nevertheless there is tendency that the Sheath and CIR curves lie higher than for another drivers and their efficiencies are higher than for MC.

Different efficiencies for different interplanetary drivers may be connected with different physical mechanisms of generation of magnetospheric activity and be a source of different reaction of magnetosphere on interplanetary drivers (Huttunen et al., 2002; Borovsky and Denton, 2006; Pulkkinen et al., 2007a; Despirak et al., 2009).

Acknowledgements. The authors thank the OMNI database team for available data on the interplanetary medium and magnetospheric indices. The work was in part supported by RFBR, grants 07-0200042 and 10-02-00277 and by Russian Academy of Sciences, programmes "Plasma Processes in the Solar System" and "Solar Activity and Physical Processes in the Sun-Earth System".

Topical Editor R. Nakamura thanks C. Farrugia and another anonymous referee for their help in evaluating this paper.

\section{References}

Akasofu, S.-I.: Energy coupling between the solar wind and the magnetosphere, Space Sci. Rev., 28, 121-190, 1981.

Alves, M. V., Echer, E., and Gonzalez, W. D.: Geoeffectiveness of corotating interaction regions as measured by Dst index, J. Geophys. Res., 111, A07S05, doi:10.1029/2005JA011379, 2006.

Borovsky, J. E. and Denton, M. H.: Differences between CMEdriven storms and CIR-driven storms, J. Geophys. Res., 111, A07S08, doi:10.1029/2005JA011447, 2006.

Burton, R. K., McPherron, R. L., and Russell, C. T.: An empirical relationship between interplanetary conditions and Dst, J. Geophys. Res., 80, 4204-4214, 1975.

Crooker, N. U., Gosling, J. T., Bothmer, V., Forsyth, R. J., Gazis, P. R., Hewish, A., Horbury, T. S., Intriligator, D. S., Jokipii, J. R., Kota, J., Lazarus, A. J., Lee, M. A., Lucek, E., Marsch, E., Posner, A., Richardson, I. G., Roelof, E. C., Schmidt, J. M., Siscoe, G. L., Tsurutani, B. T., and Wimmer-Schweingruber, R. F.: CIR Morphology, Turbulence, Discontinuities, and Energetic Particles, Space Sci. Rev., 89(1/2), 179-220, 1999.

Davis, C. J., Wild, M. N., Lockwood, M., and Tulunay, Y. $\mathrm{K}$.: Ionospheric and geomagnetic responses to changes in IMF $B_{Z}$ : a superposed epoch study, Ann. Geophys., 15, 217-230, doi:10.1007/s00585-997-0217-9, 1997.

Denton, M. H., Thomsen, M. F., Korth, H., Lynch, S., Zhang, J. C., and Liemohn, M. W.: Bulk plasma properties at geosynchronous orbit, J. Geophys. Res., 110, A07223, doi:10.1029/2004JA010861, 2005.

Denton, M. H., Borovsky, J. E., Skoug, R. M., Thomsen, M. F., Lavraud, B., Henderson, M. G., McPherron, R. L., Zhang, J. C., and Liemohn, M. W.: Geomagnetic storms driven by ICMEand CIR-dominated solar wind, J. Geophys. Res., 111, A07S07, doi:10.1029/2005JA011436, 2006.

Despirak, I. V., Lubchich, A. A., Yahnin, A. G., Kozelov, B. V., and Biernat, H. K.: Development of substorm bulges during different solar wind structures, Ann. Geophys., 27, 1951-1960, doi:10.5194/angeo-27-1951-2009, 2009.

Dungey, J. W.: Interplanetary Magnetic Field and the Auroral Zones, Phys. Rev. Lett., 6, 47-48, 1961.

Echer, E. and Gonzalez, W. D.: Geoeffectiveness of interplanetary shocks, magnetic clouds, sector boundary crossings and their combined occurrence, Geophys. Res. Lett., 31, L09808, doi:10.1029/2003GL019199, 2004.

Fairfield, D. H. and Cahill, Jr., L. J.: The transition region magnetic field and polar magnetic disturbances, J. Geophys. Res., 71, 155169, 1966.

Gonzalez, W. D. and Echer, E.: A study on the peak Dst and peak negative $\mathrm{Bz}$ relationship during intense geomagnetic storms, Geophys. Res. Lett., 32, L18103, doi:10.1029/2005GL023486, 2005.

Gonzalez, W. D., Tsurutani, B. T., and Clua de Gonzalez, A. L.: Interplanetary origion of geomagnetic storms, Space Sci. Rev., 88, 529-562, 1999.

Gosling, J. T. and Pizzo, V. J.: Formation and Evolution of Corotating Interaction Regions and their Three Dimensional Structure, Space Sci. Rev., 89(1/2), 21-52, 1999.

Gosling, J. T., McComas, D. J., Phillips, J. L., and Bame, S. J.: Geomagnetic activity associated with Earth passage of interplanetary shock disturbances and coronal mass ejections, J. Geophys. Res., 96(A5), 7831-7839, 1991. 
Huttunen, K. E. J. and Koskinen, H. E. J.: Importance of postshock streams and sheath region as drivers of intense magnetospheric storms and high-latitude activity, Ann. Geophys., 22, 1729-1738, doi:10.5194/angeo-22-1729-2004, 2004.

Huttunen, K. E. J., Koskinen, H. E. J., and Schwenn, R.: Variability of magnetospheric storms driven by different solar wind perturbations, J. Geophys. Res., 107, 1121, doi:10.1029/2001JA900171, 2002.

Huttunen, K. E. J., Koskinen, H. E. J., Karinen, A., and Mursula, K.: Asymmetric development of magnetospheric storms during magnetic clouds and sheath regions, Geophys. Res. Lett., 33, L06107, doi:10.1029/2005GL024894, 2006.

Ilie, R., Liemohn, M. W., Thomsen, M. F., Borovsky, J. E., and Zhang, J.: Influence of epoch time selection on the results of superposed epoch analysis using ACE and MPA data, J. Geophys. Res., 113, A00A14, doi:10.1029/2008JA013241, 2008.

Kamide, Y., Yokoyama, N., Gonzalez, W., Tsurutani, B., Daglis, I., Brekke, A., and Masuda, S.: Two-step development of geomagnetic storms, J. Geophys. Res., 103, 6917-6921, doi:10.1029/97JA03337, 1998

King, J. H. and Papitashvili, N. E.: Solar Wind Spatial Scales in Comparisons of Hourly Wind and ACE Plasma and Magnetic Field Data, J. Geophys. Res., 110(A2), A02209, doi:10.1029/2004JA010804, 2004,

Lepping, R. P., Wu, C.-C., and Berdichevsky, D. B.: Automatic identification of magnetic clouds and cloud-like regions at $1 \mathrm{AU}$ : occurrence rate and other properties, Ann. Geophys., 23, 26872704, doi:10.5194/angeo-23-2687-2005, 2005.

Liemohn, M. W., Zhang, J.-C., Thomsen, M. F., Borovsky, J. E., Kozyra, J. U., and Ilie, R.: Plasma properties of superstorms at geosynchronous orbit: How different are they?, Geophys. Res. Lett., 35, L06S06, doi:10.1029/2007GL031717. 2008.

Loewe, C. A. and Prolss, G. W.: Classification and mean behavior of magnetic storms, J. Geophys. Res., 102(A7), 14209-14214, 1997.

Lopez, R. E. and Freeman, J. W.: Solar wind proton temperaturevelocity relationship, J. Geophys. Res., 91, 1701-1705, 1986.

Lyatsky, W. and Tan, A.: Solar wind disturbances responsible for geomagnetic storms, J. Geophys. Res., 108(A3), 1134, doi:10.1029/2001JA005057, 2003.

Lynch, B. J., Zurbuchen, T. H., Fisk, L. A., and Antiochos, S. K.: Internal structure of magnetic clouds: Plasma and composition, J. Geophys. Res., 108(A6), 1239, doi:10.1029/2002JA009591, 2003.

Maltsev, Y. P., Arykov, A. A., Belova, E. G., Gvozdevsky, B. B., and Safargaleev, V. V.: Magnetic Flux Redistribution in the Storm Time Magnetosphere, J. Geophys. Res., 101, 7697-7704, 1996.

Miyoshi, Y. and Kataoka, R.: Ring current ions and radiation belt electrons during geomagnetic storms driven by coronal mass ejections and corotating interaction regions, Geophys. Res. Lett., 32, L21105, doi:10.1029/2005GL024590, 2005.

Pulkkinen, T. I., Partamies, N., Huttunen, K. E. J., Reeves, G. D., and Koskinen, H. E. J.: Differences in geomagnetic storms driven by magnetic clouds and ICME sheath regions, Geophys. Res. Lett., 34, L02105, doi:10.1029/2006GL027775, 2007a.

Pulkkinen, T. I., Partamies, N., McPherron, R. L., Henderson, M., Reeves, G. D., Thomsen, M. F., and Singer, H. J.: Comparative statistical analysis of storm time activations and sawtooth events, J. Geophys. Res., 112, A01205, doi:10.1029/2006JA012024, 2007b.

Rostoker, G. and Falthammar, C.-G.: Relationship between changes in the interplanetary magnetic field and variations in the magnetic field at the earth's surface, J. Geophys. Res., 72, 5853-5863, 1967.

Russell, C. T., McPherron, R. L., and Burton, R. K.: On the cause of magnetic storms, J. Geophys. Res., 79, 1105-1109, 1974.

Taylor, J. R., Lester, M., and Yeoman, T. K.: A superposed epoch analysis of geomagnetic storms, Ann. Geophys., 12, 612-624, doi:10.1007/s00585-994-0612-4, 1994.

Tsurutani, B. T. and Gonzalez, W. D.: The interplanetary Causes of Magnetic Storms: A Review, in: Magnetic Storms, edited by: Tsurutani, B. T., Gonzalez, W. D., and Kamide, Y., Amer. Geophys. Union Press, Washington D.C., Mon. Ser., 98, 1997, p. 77, 1997.

Tsurutani, B. T., Gonzalez, W. D., Tang, F., Akasofu, S. I., and Smith, E. J.: Origin of Interplanetary Southward Magnetic Fields Responsible for Major Magnetic Storms Near Solar Maximum (1978-1979), J. Geophys. Res., 93(A8), 8519-8531, 1988.

Tsurutani, B. T., Gonzalez, W. D., Gonzalez, A. L. C., Guarnieri, F. L., Gopalswamy, N., Grande, M., Kamide, Y., Kasahara, Y., Lu, G., Mann, I., McPherron, R., Soraas, F., and Vasyliunas, V.: Corotating solar wind streams and recurrent geomagnetic activity: A review, J. Geophys. Res., 111, A07S01, doi:10.1029/2005JA011273, 2006.

Turner, N. E., Cramer, W. D., Earles, S. K., and Emery, B. A.: Geoefficiency and energy partitioning in CIR-driven and CMEdriven storms, J. Atmos. Solar-Terr. Phys., 71, 1023-1031, 2009.

Vichare, G., Alex, S., and Lakhina, G. S.: Some characteristics of intense geomagnetic storms and their energy budget, J. Geophys. Res., 110, A03204, doi:10.1029/2004JA010418, 2005.

Vieira, L. E. A., Gonzalez, W. D., Echer, E., and Tsurutani, B. T.: Storm-intensity criteria for several classes of the driving interplanetary structures, Solar Phys., 223(1-2), 245-258, 2004.

Wimmer-Schweingruber, R. F., Crooker, N. U., Balogh, A., Bothmer, V., Forsyth, R. J., Gazis, P., Gosling, J. T., Horbury, T., Kilchenmann, A., Richardson, I. G., Richardson, J. D., Riley, P., Rodriguez, L., Von Steiger, R., Wurz, P., and Zurbuchen, T. H.: Understanding Interplanetary Coronal Mass Ejection Signatures, Space Sci. Rev., 123(1-3), 177-216, 2006.

Yermolaev, Yu. I. and Yermolaev, M. Yu.: Statistical Relationships between Solar, Interplanetary, and Geomagnetospheric Disturbances, 1976-2000, Cosmic Res., 40(1), 1-14, 2002.

Yermolaev, Yu. I. and Yermolaev, M. Yu.: Statistic study on the geomagnetic storm effectiveness of solar and interplanetary events, Adv. Space Res., 37(6), 1175-1181, doi:10.1016/j.asr.2005.03.130, 2006.

Yermolaev, Yu. I., Yermolaev, M. Yu., and Nikolaeva, N. S.: Comparison of interplanetary and magnetospheric conditions for CIR-induced and ICME-induced magnetic storms, European Geosciences Union, Geophys. Res. Abstr., 7, 01064, 2005.

Yermolaev, Yu. I., Yermolaev, M. Yu., and Lodkina, I. G.: Comment on "A statistical comparison of solar wind sources of moderate and intense geomagnetic storms at solar minimum and maximum" by Zhang, J.-C., M. W. Liemohn, J. U. Kozyra, M. F. Thomsen, H. A. Elliott, and J. M. Weygand, J. Geophys. Res., 2006, preprint at http://arxiv.org/abs/physics/0603251, 2006.

Yermolaev, Yu. I., Yermolaev, M. Yu., Lodkina, I. G., and Nikolaeva, N. S.: Statistic study of heliospheric conditions resulting 
in magnetic storm, Cosmic Res., 45(1), 1-8, 2007a.

Yermolaev, Yu. I., Yermolaev, M. Yu., Lodkina, I. G., and Nikolaeva, N. S.: Statistic study of heliospheric conditions resulting in magnetic storm, 2. Cosmic Res., 45(6), 489-498, $2007 \mathrm{~b}$.

Yermolaev, Yu. I., Yermolaev, M. Yu., Nikolaeva, N. S., and Lodkina, L. G.: Interplanetary conditions for CIR-induced and MCinduced geomagnetic storms, Bulg. J. Phys., 34, 128-135, 2007c.

Yermolaev, Yu. I., Nikolaeva, N. S., Lodkina, I. G., and Yermolaev, M. Yu.: Catalog of Large-Scale Solar Wind Phenomena during 1976-2000, Cosmic Res., 47(2), 81-94, 2009.

Yermolaev Yu. I., Lodkina, I. G., Nikolaeva, N. S., and Yermolaev, M. Yu.: Statistical study of interplanetary condition effect on geomagnetic storms, Cosmic Res., 48(6), 485-500, 2010a.

Yermolaev, Yu. I., Nikolaeva, N. S., Lodkina, I. G., and Yermolaev, M. Yu.: Relative occurrence rate and geoeffectiveness of largescale types of solar wind, Cosmic Res., 48(1), 1-30, $2010 \mathrm{~b}$.
Yokoyama, N. and Kamide, Y.: Statistical nature of geomagnetic storms, J. Geophys. Res., 102(A7), 14215-14222, 1997.

Zhang, J.-C., Liemohn, M. W., Kozyra, J. U., Thomsen, M. F., Elliott, H. A., and Weygand, J. M.: A statistical comparison of solar wind sources of moderate and intense geomagnetic storms at solar minimum and maximum, J. Geophys. Res., 111, A01104, doi:10.1029/2005JA011065, 2006.

Zhang, J., Richardson, I. G., Webb, D. F., Gopalswamy, N., Huttunen, E., Kasper, J. C., Nitta, N. V., Poomvises, W., Thompson, B. J., Wu, C.-C., Yashiro, S., and Zhukov, A. N.: Solar and interplanetary sources of major geomagnetic storms (Dst $\leq$ -100 nT) during 1996-2005, J. Geophys. Res., 112, A10102, doi:10.1029/2007JA012321, 2007. 